\title{
LA PROPUESTA ESTÉTICA DE SAMUEL ROVINSKI: LA CONCEPCIÓN DE UN TEATRO POPULAR EN LAS FISGONAS DE PASO ANCHO
}

\author{
ON SAMUEL ROVINSKI'S AESTHETICS: THE CONCEPTION OF \\ POPULAR THEATRE IN LAS FISGONAS DE PASO ANCHO
}

Geaninni Ruiz Ulloa*

\section{RESUMEN}

La presente investigación expone la propuesta estética de Samuel Rovinski como dramaturgo; los conceptos y las premisas que utiliza en sus textos con el fin de vislumbrar la concepción de teatro popular expuesta en la época de los setenta, no exclusiva de él sino de una generación de autores. Asimismo, se realiza una caracterización de los recursos formales que se emplearon en la composición del texto dramático Las fisgonas de Paso Ancho.

Palabras clave: Rovinsky, teatro popular, recursos formales, sociedad, dramaturgia costarricense.

\begin{abstract}
This article approaches the principles of Samuel Rovinski'aesthectic as playwright, and the concepts and premises that he uses for his plays in order to discern the conception of popular theatre exposed in the seventies that is not exclusive of Rovinsky's play, and belongs to a whole generation of playwrights. In addition, this article includes a characterization of the formal recourses that were used in the composition of the play Las fisgonas de Paso Ancho.

Key Words: Rovinski, popular theatre, formal resourses, society, Costarrican play-writing.
\end{abstract}

Estudiante de Filología Española, Universidad de Costa Rica.

Correo electrónico: geaninniruiz@gmail.com

Recepción: 27/9/2013. Aceptación: 25/10/2013. 


\section{Entre las bambalinas}

La década de los setenta ha sido considerada un momento fundacional para la constitución de la dramaturgia costarricense; pues se centró en abrir nuevos derroteros para el acercamiento de un público nacional hasta entonces desprovisto de una tradición escénica teatral. En otras épocas, se realizaron intentos valiosos por encausar un camino menos efímero del espectáculo teatral, sin embargo, no contaron con suficientes recursos económicos, ni instituciones que respaldaran el trabajo de los $\operatorname{artistas}^{1}$.

De hecho, en esos años, el panorama cultural se enriqueció por distintas iniciativas que se fueron gestando. Verbigracia, la presencia de pequeñas agrupaciones independientes permitió que el público nacional pudiera disfrutar de obras clásicas. A su vez, fue vital el arribo de artistas extranjeros, provenientes mayoritariamente del sur, quienes incorporaron nuevas técnicas actorales. Además, los grupos de aficionados empezaron a ser auspiciados por alguna institución pública ${ }^{2}$. Un hecho importante dentro de la historia teatral resultó ser la celebración del Primer Festival Cultural Centroamericano, organizado por el Consejo Superior Universitario Centroamericano (CSUCA), el 31 de agosto de 1968, evento que sirvió para la culminación de un estudio formal sobre el teatro, creándose así la Escuela de Artes Dramáticas de la Universidad de Costa Rica.

Esta eclosión en el ámbito teatral se vio mediada por políticas favorables al arte escénico. Además, del surgimiento de tres figuras claves: Daniel Gallegos, Samuel Rovinski y Alberto Cañas. Pues aparte de ser dramaturgos, también fungen como gestores culturales. Por ejemplo, Alberto Cañas es nombrado Ministro de Cultura en 1970, dentro de su gestión logra establecer la Compañía Nacional de Teatro y otra serie de medidas para fomentar el interés por el teatro ${ }^{3}$. Daniel Gallegos dirige la Escuela de Artes Dramáticas desde 1969 hasta 1976. Por último, Samuel Rovinski trabaja muy de la mano con los grupos independientes "El Arlequín” y "Las Máscaras", entre otros.
Según Guillermo Barzuna, el trío anteriormente mencionado se entronca en el establecimiento de una propuesta que aboga por la popularización del fenómeno teatral, caracterizándose principalmente por: a) una preferencia por el espacio abierto como lugar ideal para la representación antes que una reducida sala, por lo que el escenario se traslada a parques, clínicas o salones comunales; b) una consigna por la creación colectiva antes que la individual, y c) un apoyo económico estatal más establece a compañías independientes para el desarrollo de propuestas teatrales.

Este interés por difundir el teatro no fue único de Costa Rica, sino - al contrariose comprende como una manifestación más de la realidad cultural latinoamericana de ese entonces, que se preocupó por la vinculación del arte con la sociedad. Partiendo de lo anterior, proponemos una lectura de los textos de Rovinski a partir de la concepción del teatro popular, pues su forma de concebir el arte teatral entra en diálogo con otros movimientos de la región. Además, no solo los contenidos sociales y políticos que acompañan las obras son importantes, sino también la forman en que estas se construyen, hecho que buscamos ejemplificar con el texto Las fisgonas de Paso Ancho de Samuel Rovinski.

Chesney Lawrence (1995) propone una tentativa periodización del teatro popular latinoamericano, estableciendo su comienzo en 1955 y sus últimas manifestaciones en 1985, puesto que durante esas décadas las realidades de los países latinoamericanos experimentaron grandes cambios socio-políticos. El término teatro popular ${ }^{4}$ como una categoría no presenta un desarrollo homogéneo, pues cada país aportó rasgos variopintos en su modo de representación teatral, no obstante, la propuesta de Chesney Lawrence permite establecer un cuadrante con lineamentos en común que conducen a una nueva visión del hecho teatral y su repercusión en el medio social - como él mismo afirma - :

Este teatro popular expresa cabalmente los anhelos, intereses y problemas del pueblo. En efecto, en esta época el teatro popular se definió, esencialmente en función de las condiciones sociales, económicas 
y culturales, distanciándose del folklore, de lo indígena y de lo religioso, que en sí constituyen expresiones tradicionales del pueblo, pero que no conformaron el centro de sus proposiciones, su característica más interesante fue, por tanto, la adopción en sus creaciones de una perspectiva de cambio social, considerando el interés del pueblo, aspecto que determina su intencionalidad dramática popular (1995: 110).

La aparición de posturas políticas y cambios sociales en la realidad latinoamericana condujo a la necesidad de buscar un arte que tomará una postura ideológica. A propósito de lo anterior, César Rengifo - dramaturgo venezolano- afirma que el teatro "tiene que ser un arma de combate que ayude a la revolución. Debe ser un teatro al servicio de estas luchas, sin que deje de tener una calidad estética" (citado por Chesney, 1995: 27). Este aspecto ideológico promulga un compromiso social que se asocia comúnmente una postura de izquierda.

Entre las principales innovaciones a la representación teatral aportadas por el teatro popular se pueden mencionar las siguientes muy similares a las de Barzuna- : a) la creación colectiva como directriz de la acción dramática, dando como resultado nuevas herramientas de comunicación con el público; b) la notoriedad de la preferencia de un lenguaje teatral que busca una identificación con las clases populares e incorporación de otros códigos semióticos a la escena (música, canciones, imágenes) y c) el teatro busca salir del ámbito meramente estético con el fin de tener una repercusión real.

El sentido crítico de la dramaturgia de este periodo nos permite comprender la carga social y política de los textos, la cual se inscribe según la realidad de cada dramaturgo. En el caso de Costa Rica, Álvaro Quesada señala que la producción de Samuel Rovinski puede ser catalogada en dos vertientes, las cuales se fecundan e interrelacionan: la primera corresponde a un gusto por el lenguaje y la vida popular, adaptando el sainete costumbrista a la crítica social y política de situaciones contemporáneas en obras como Gobierno de alcoba (1967) o Las fisgonas de Paso Ancho (1971); la segunda "manifiesta su preocupación por los temas políticos y sociales, y explora las relaciones conflictivas entre el individuo, las estructuras sociales y las instancias del poder" en obras como La Atlántica o El Laberinto, Un modelo para Rosaura (1975).

María Lourdes Cortés menciona, en torno a la producción del trío Cañas-GallegosRovinski, los ejes temáticos de los autores a partir de una lectura ideológica de sus obras, apunta a que los textos de Rovinski se mueven dentro de la oposición colectivo/ individual, pues: "En algunos de sus textos se plantea la lucha como posible (y único medio) para alcanzar la plenitud de espacios o personajes siempre carenciales. Esta plenitud nunca es alcanzada, pero la posibilidad de logro se establece mediante la lucha por obtener beneficios de una colectividad" (1988: 24). A su vez, la estudiosa indica que el discurso dramático de Rovinski evidencia un "señalamiento del poder y los efectos de los medios de comunicación de masas en nuestro país" (1988: 29).

\section{Rovinski y su propuesta estética}

La formulación de una teoría sobre la propuesta artística de un determinado autor corresponde a un hecho que inicialmente puede partir del autor mismo, debido a que este reflexionará, generalmente, a posteriori, de cómo ha realizado su obra y bajo qué lineamientos se ha guiado. Un ejemplo famoso es el norteamericano Edgar Allan Poe, quien en su conocido ensayo "The Philosophy of Composition" explica cómo escribe su poema The Raven. Una ilustración más contemporánea es Umberto Eco, quien a partir del éxito de $E l$ nombre de la rosa y a petición de cientos de lectores, escribe Apostillas de El nombre de la rosa como respuesta ante la serie de preguntas sobre el significado de los símbolos del texto, como por ejemplo, la rosa. En este opúsculo se reafirma su carácter como autor y la libertad interpretativa que busca dejar en su texto, como el mismo menciona 


\begin{abstract}
El autor no debe interpretar. Pero puede contar por qué y cómo ha escrito. Los llamados escritos de poética no siempre sirven para entender la obra que los ha inspirado, pero permiten entender cómo se resuelve el problema técnico de la producción de una obra. (1988: 10)
\end{abstract}

Eco apunta a que un autor no puede decir cuál es el significado de su obra, sino los parámetros que utiliza para construirla; pues, ese constituye el problema de la génesis literaria. Dentro de esa misma premisa, proponemos una construcción de la propuesta estética de Samuel Rovinski por medio de tres artículos de su autoría publicados de manera discontinua en la revista Escena de 1979 a 1989, en los cuales se pueden delinear los con los conceptos y lineamientos que caracterizan su obra. Los principales ejes en que se articula su forma de concebir el teatro son:

a) La noción de la obra dramática

b) La finalidad de la dramatización teatral

c) La recepción del público

Rovinski se plantea el problema de génesis literaria: ¿En qué se basa el autor para la creación de sus obras? ¿En un artificio imaginativo o un reflejo de la realidad? Para el autor, el texto dramático surge de una identificación con la realidad misma, la obra como mimesis, conlleva a que el texto se produzca dentro de los parámetros y los instituyentes sociales conocidos por los espectadores.

Lukács considera que la literatura debe reflejar, es decir, expresar una estructura mental mediante palabras, pues el reflejo no es solo superficial, sino dinámico, vivido de la realidad (citado por Selden, 120). En este caso, la insistencia del verbo reflejar en Rovinski debe entenderse como la representación de un acontecer inmediato de la realidad, de una temporalidad presente, de los problemas y vicisitudes del "pueblo" debido a que se busca una completa identificación con el público; además, sus obras plantean superficialmente la estructura dinámica de poder que subyace en la sociedad costarricense. De hecho, Rovinski manifiesta una gran preocupación por lograr la identificación entre lo escenificado y el público, para él "la sociedad es el teatro de lo cotidiano" (1984: 25).

En búsqueda de esa referencialidad espacial, temporal y temática que tiene la obra dramática (tomando en cuenta el texto como su representación escénica) su propuesta se inscribe dentro del teatro popular, puesto que reitera el interés por la representación de lo inmediato, es decir, del statu quo de la realidad de una mayoría popular.

Como dramaturgo que cree en el teatro popular
(no de masas), en el deber ineludible de explorar y
señalar la verdad de los acontecimientos sociales, en
la misión de un teatro que educa mientras entretiene
y que sabe despertar el espíritu crítico del público,
me siento comprometido a seguir el camino por
mi últimas obras que se acercan cada vez más a la
dramatización de lo inmediato (1984: 25)

El concepto de teatro popular tiene validez dentro de la concepción de un teatro de élite, este binomio se formula dentro de una noción de cultura selectiva, en la cual las instituciones de arte están dirigidas a una sola clase, aquella que cuenta con la tenencia de los medios de producción, en otras palabras, arte burgués. En ese sentido, Rovinski crítica toda aquella producción teatral que solo busque ser reproducida o entendida para el disfrute de un solo grupo, en este caso, considera que antes de los setenta, la mayoría de la producción teatral nacional se creaba, representaba y reproducía para un único público:

El teatro parecía estar condenado a mantenerse
encerrado en una prisión intelectual de clase media,
como sucedió con una parte de la narrativa (1979: 50)
El espacio escénico permite concentrar la atención
del espectador sobre los aspectos de la vida real que
normalmente pasan inadvertidos o que se revisten de
una falsa trascendencia (1984: 24).

Meyerhold desde un enfoque meramente estructural define el teatro en cuatro fundamentos: autor, director, actor y espectador; a partir de estos se realizan distintas interacciones que permiten el fenómeno teatral. En el teatro de Rovinski, la relación entre actor-espectador se sobrepone a las demás, pues por medio de la identificación de los personajes, de su forma de expresarse, de las situaciones, de los lugares; se 
logra acercar al público nacional a un contacto con lo teatral. Según Rovinski, el público "quiere verse en el escenario y considerar una interpretación de los problemas de su tiempo. Busca una explicación del acontecer cotidiano y de su angustia existencial" (1984: 25). Por tanto, las obras dramáticos se vuelven un espacio para denunciar y señalar los problemas nacionales que viven las clases populares.

Cabe rescatar por último, el elemento de la risa como medio para naturalizar la realidad y además, de ser un recurso que sirve para la denuncia. Para ello, Rovinski se basa en los presupuestos de Henri Bergson en su Tratado de la Risa, en el cual se expone que "la risa no puede ser absolutamente justa y no debe ser tampoco buena. Su misión es la de intimidar humillando" (1984: 130). En términos bergosonianos, la risa permite evidenciar una conducta con el fin de que sea corregida; pues el objetivo es el despertar la conciencia de los espectadores sobre aquello que parece risible y natural.

\section{Las fisgonas de Paso Ancho y algunas consideraciones de forma}

La obra Las fisgonas de Paso Ancho, sainete musical de 50 minutos, resultó elegida dentro de una convocatoria organizada por la Escuela de Artes Dramáticas y el Teatro Universitario en 1970 dirigida a los dramaturgos nacionales. Ambas instituciones estaban desarrollando un programa de extensión cultural a las comunidades. Rovinski explica que "la primera etapa consistiría en llevar teatro a los barrios de la capital y continuar con la formación de grupos aficionados que serían sostenidos por sus propias comunidades" (1984: 50). Además, debido a la escasez de salas de teatro, las obras del programa debían ser de fácil montaje, de extensión corta, con un lenguaje sencillo y personajes de rápida identificación.

Las fisgonas de Paso Ancho fue estrenada en 1971 en la escuela de Paso Ancho. Según Rovinski, la obra contó una recepción favorable del público, cuyo éxito se mide en cantidad aproximada de 36000 espectadores y más de 500 representaciones. La obra trata de la vida de tres vecinas del barrio de Paso Ancho, las cuales tienen fama de entrometerse en la vida de sus vecinos, por esa razón, son conocidas como "las fisgonas". El texto comienza con una de ellas escuchando detrás de la puerta de la casa de los Alfaro. Luego, aparecen las otras fisgonas preguntando de qué se ha enterado, pues como buenas cristianas les preocupa el bienestar de sus prójimos. En eso, se escuchan unos gritos provenientes de la casa. Inquietas, las fisgonas piensan que pueden estar matando a alguien. Así que por la sugerencia de un niño que vende pejibayes, deciden llamar a la guardia rural. Sin embargo, lo que parecía un problema de convivencia familiar termina convirtiéndose en noticia nacional. El polvorín informativo resulta una representación paródica de una sociedad que sobrevalora la mentira del espectáculo antes que la integridad de sus miembros.

Generalmente, la crítica se ha dedicado a señalar la denuncia que se explícita en la obra sobre el papel de los medios de comunicación, el abuso en su injerencia en la vida pública y la distorsión del concepto de verdad ${ }^{5}$. Sin embargo, el compromiso social que emprende el texto, no solo se lee en su contenido, sino también en su estructura. Los recursos formales que se enumeran a continuación se formulan a partir del texto, pues además del contenido como preocupación de la propuesta estética, también el cómo se presenta corresponde a ese hecho de denuncia.

a) La utilización de un lenguaje que busca ser identificado como cotidiano y coloquial

Una de las premisas de la producción de Bertold Brecht es que "el pueblo debe ser destinatario de todo arte". En otras palabras, toda producción artística debe construirse desde el seno de las clases sociales que conforman un "pueblo". De esta manera, el lenguaje se entiende como instrumento que conlleva a la identificación del espectador con su realidad. Tomando como referencia el lineamiento brecthiano, la presencia de palabras de uso colonial se presenta desde la propia construcción 
de las obra. Pues las vecinas, cuyo papel será el de las fisgonas, utilizan un lenguaje coloquial pululado de costarriqueñismos, verbigracia:

Vecina 1: Mire, ¿por qué no se deja de vainas y llama a la poli?

Vecina 2: Yo creo que el chiquillo tiene razón.

Vecina 3: Bueno, andate para allá, a llamar a la radio patrulla (1978: 21).

Algunas palabras y frases que se presentan en los diálogos buscan referirse a la variedad propia del español de Costa Rica como: guililla, chunche, poquitico, entre otras. Además, hay una presencia de un grupo semántico de palabras relacionadas con la violencia, que se suma a la denuncia de una sociedad costarricense que se ha insensibilizado ante el amarillismo de los medios de comunicación. Por ejemplo: "Entonces le dan a su buena leñateada" (1978: 13) "ayy le dio una trompada" (1978: 19) "Debería futearte tu tata" (1978: 20) "El moteado es capaz echa al plato la roca" "Entonces el policía me agarró como sospechoso y me metió en la chirona toda la noche para que me comieran los alepatos" (1978: 21) "Al precinto, zoquete" (1978: 21).

b) La construcción de un espacio a partir de oposiciones: adentro/afuera, público/ privado, sujeto/colectivo, realidad/ fantasía

La puerta de la casa de los Alfaro se construye como el umbral de la acción, marcando el límite entre lo que pasa dentro de la casa (familia) y lo que sucede afuera, en la calle (sociedad). Herminia, adopta el papel de interpretar lo que sucede adentro, pues ella es la que cuenta a las demás vecinas el conflicto que se desarrolla en la casa. Así, lo que parecía un pleito meramente doméstico, termina convirtiéndose en noticia nacional.

Vecina 1: Pues espérese, Carmencita, y lo sabrá todo. Me arrimaré otra vez a la puerta y usted me avisa si se acerca alguien para quitarme y que no haya malentendidos.
Vecina 2: Vaya con confianza, Herminia. Arrímese a la puerta sin miedo que yo le cuidaré la espalda (1979: 9).

El desapego a la veracidad de los acontecimientos y la exagerada imaginación de las fisgonas (a raíz de su fidelidad por no perderse la programación televisiva) terminan creando el escenario en donde se representará la gran parodia social. La realidad se mira como insuficiente, se prefiere vivir en la fantasía

Vecina 3: ¿Qué tal si a Herminia no se le ocurre pegar la oreja a la puerta de los Alfaro?

Vecina 1: ¿Qué está queriendo insinuar, Marielena?

Vecina 3: Pues que tal vez nos habríamos perdido el teatro de esta noche (1978: 47)

Asimismo, la realidad de las fisgonas se permea de los estereotipos y patrones culturales imperantes en los medios de comunicación, principalmente, la televisión. De ahí que se alabe el comportamiento de Abelardo, protagonista de una telenovela, como el hijo ideal, obediente y sacrificado por su madre, ante el de Hernán, quién es un hijo desconsiderado y marido agresor. Las fisgonas desean tener un "Abelardo", evidenciando la pugna entre el ser y el deber ser:

Vecina 1: Cuando un hijo, por supuesto que sólo como Abelardo, reconoce que hizo mal en dejar abandonada a su anciana madre para seguir a una pecadora, merece no solamente el perdón de su madre, sino la bendición del cielo.

Vecina 3: Una verdad como una catedral.

Vecina 1: Dejó la mala vida al darse cuenta que habría sido engañado y volvió con su progenitora. (1979: 17)

c) Uso de personajes tipo

A pesar de que las fisgonas poseen un nombre propio, eso no es determinante para su papel, pues el nombre es un agregado más, lo significativo es realidad el rol protagónico que cumplen. Asimismo, los demás personajes encarnan hombres y mujeres sin rostro, pues cada uno pertenece a un grupo social. Por 
ejemplo, los guardias se enumeran para señalar que son personajes distintos:

\author{
Guardia 1: Capitán \\ Guardia 2: ¿Qué? \\ Guardia 1: ¿Trajeron la orden de allanamiento?
}

Guardia 2(a unos de los rurales): ¿Trajeron la orden de allanamiento?

Guardia Rural: No. Como salimos tan a la carrera, se nos olvidó pasar por ella.

Guardia 1: ¿Idiay, y ahora cómo vamos a entrar?

Guardia 2: (rascándose la cabeza) Ah, caramba. (1978: 33)

d) El apego temporal a un presente, la acción ocurre en un "ahora"

La acción de la obra es cronológica y lineal, en este sentido, seguiría los patrones del arte teatral clásico. No obstante, este hecho resulta estar más acorde con el afán de presentar un montaje fácil $\mathrm{y}$, a su vez, parte de las consideraciones estéticas de Rovinski por presentar la dramatización de lo inmediato.

Radioperiodista: Muy bien, doña María. Muchas gracias, han escuchado la voz de una de las víctimas. Amigos radioescuchas, la calle se encuentra llena de guardias civiles. La tensión aumenta. Ah, y por ahí vienen entrando los guardias rurales pedidos como refuerzo para vencer al bruto. Y por aquí vemos a nuestro amigo el capitán Cordero (a la Guardia 2) capitán Cordero, capitán Cordero, por favor, présteme unos instantes de su valioso tiempo. (1978: 31)

e) Uso de elementos que permitan una referencialidad inmediata: canciones, anuncios, personajes icónicos de programas de radio o televisión

Como se explicó en el punto $b$ la marcada influencia del medio televisivo provoca que durante el desarrollo de la obra se hagan presentes las menciones a personajes de novelas y series, anuncios y comerciales de productos que provoquen en el espectador la recepción de un marco de referencia común. Además, se incorporan pequeñas canciones con el fin de explicar o ilustrar alguna acción de los personajes. Como lectores contemporáneos muchos de los referentes que se mencionan en la obra, no son parte de nuestro medio cultural. No obstante, la estructura de la obra se construye para que cuando sea interpretada pueda sustituirse tal referente a uno más conocido por el público.

Vecina 2: Ah, sí, claro, el del doctor aquél, corronguísimo ¿Cómo se llama?

Vecina 1: Bill Collins.

Vecina 2: Eso. En canal 7, después de las noticias, por cierto, son aburridísimas.

Vecina 3: Pues yo no veo ese canal desde que dan Simplemente María. (1978: 20)

\section{Conclusiones}

La época de los setenta representa un crecimiento en el desarrollo de la producción teatral nacional, constituyó un buen arranque para que el acercamiento de un público nacional desprovisto de una tradición cultural sobre el teatro. La presencia de grupos independientes y de programas institucionales apoyados por el estado permitió extrapolar el espectáculo teatral a escenarios cotidianos.

La propuesta de Rovinski, su forma particular de entender lo popular como la dramatización de lo inmediato, busca provocar en el espectador un despertar sobre los acontecimientos que suceden en su realidad. Esta preocupación del dramaturgo nacional se inscribe dentro de un panorama latinoamericano, que a raíz de los cambios políticos y sociales del momento, concibió un arte comprometido con las mayorías populares que se compartió también en otras partes del continente. Cabe mencionar las propuestas de Augusto Boal, César Rengifo y Gianfrancesco Guarnieringifo.

Este trabajo es un primer intento de querer integrar un fenómeno de la literatura costarricense dentro de un panorama mucho más amplio que el tradicionalmente considerado como localista; pues al comprender que la época de los setenta es parte de la reflexión de dramaturgos de la región latinoamericana que se entronca bajo la denominación de 
teatro popular, podemos poner en diálogo los distintos procesos creativos. En nuestro caso, no profundizamos en ese aspecto, pues nos centramos en la explicación de los conceptos que utiliza Rovinski a la hora de concebir el texto dramático. No obstante, nos parece importante invitar a la aparición de nuevos trabajos que apunten por un paradigma más interregional que busque entender los textos literarios no solo dentro de su contexto en específico, sino también en un marco mayor de referencia.

Además, por medio de la caracterización de los recursos formales de la obra Las fisgonas de Paso Ancho buscamos demostrar que la forma es sumamente valiosa para el factor crítico del texto, pues cada elemento no es fortuito, sino que se enmarca dentro de una concepción de lo teatral como la representación de lo inmediato. De esta forma, presenciamos como un problema doméstico se convierte en noticia nacional por causa de la imaginación de unas viejas chismosas, las cuales representan un personaje popular de cualquier barrio josefino.

\section{Notas}

1. A modo de ilustración: en 1951 se produce el primer intento de crear el Teatro Universitario, sin embargo, el grupo no contaba con una dirección artística estable, la mayoría de sus direcciones duraban muy poco y las obras que se representaban tampoco seguían una evolución progresiva, sino más bien se producían según algún criterio de uno de los miembros.

2. Algunos de ellos fueron el Teatro de la Prensa, el Teatro "Las Máscaras" conducido por Luccio Ranucci, y el Teatro de la Caja del Seguro Social, liderado por el poeta Alfredo Sancho.

3. Rovinski en su artículo "En busca del público perdido" menciona que el Ministerio de Cultura, Juventud y Deportes ponía los precios de las entradas para el teatro más baratos que los del cine. Igualmente, ofrecía que después de una presentación transporte de regreso para el público asistente, destinado especialmente para los habitantes de barrios josefinos.

4. Chesney rastrea tres influencias previas sobre el concepto de teatro popular: a) un primer teatro popular que se desarrolla a partir de conceptos europeos, posterior a la Revolución Francesa, ya que se efectúa un proceso de democratización del teatro, auspiciado por la burguesía del momento que con aires de progreso abre las puertas del patrimonio cultural exclusivo de las clases privilegiadas a las clases bajas; b) un teatro popular con énfasis político principalmente desarrollado a principios de siglo XX en los albores de la industrialización y tecnificación, algunos de sus representantes como Weimar, Piscator y Brecht basan su propuesta a partir de un compromiso social; dos etapas de este fueron la interpretación por los gustos populares y la relación de organizaciones culturales que levanten su propio proyecto escénico; c) por último, la propuesta de Augusto Boal quién propone un categorización exhaustiva del desarrollo del teatro popular a partir de contexto latinoamericano desde su experiencia como actor, dramaturgo y director.

5. Bajo esa línea se agrupan los trabajos de Magda Zavala (1972), Guillermo Barzuna (1984) y María Lourdes Cortés (1988).

\section{Bibliografía}

Barzuna, Guillermo. 1984. Recuento de un teatro popular en los años setentas. Revista Escena 9: 20-24.

Bell, Carolyn \& Fumero, Patricia. 2000. Drama contemporáneo costarricense: 1980-2000. San José: Editorial de la Universidad de Costa Rica.

Calderón, Juan Carlos. 2006. Aportes para una historiografía del teatro costarricense Revista Escena 29: 83- 93.

Chesney, Lawrence. 1995. Teatro popular latinoamericano 1955- 1985. Caracas: Centro de Creación e Investigación Teatral. 
Cros, Edmond. 1986. Literatura, ideología y sociedad. Madrid: Editorial Gredos.

Cortés Pacheco, María Lourdes.1988. En torno a la producción de sentido de los textos dramáticos de Cañas, Gallegos y Rovinski. En Kañina 12: 19-33.

Díaz, Miguel. 1981. Hacia un teatro popular costarricense. Revista Escena 6: 19-20.

Eco, Humberto.1988. Apostillas a El nombre de la rosa. Editorial Lumen.

Herzefeld, Anita \& Cajiao, Teresa. 1973. El teatro de hoy en Costa Rica. San José: Editorial de Costa Rica.

Mora, Arnoldo. 1985. ¿Existe un teatro popular en Costa Rica? Revista Escena 7: 1-2.

Quesada Soto, Álvaro. La dramaturgia costarricense de fin de siglo. Revista Comunicación,http://www.tec.ac.cr/ sitios/Docencia/ciencias_lenguaje/ revista_comunicacion/revista\%20vieja/ VIII20Congreso $\% 20-\% 20$ Carmen $\% 20$ Naranjo/ponencias/literatura/ otrosautores/pdf\%27s/aquesada.pdf

Rovinski, Samuel. 1984. Dramatización de lo inmediato. Revista Escena 9: 24-25.
Rovinski, Samuel. 1979. En búsqueda del público perdido. Revista Escena 4: 49-54.

Rovinski, Samuel. 1987. El sentido de lo cómico. Revista Escena 2: 126-131.

Rovinski, Samuel. 1978. Las fisgonas de Paso Ancho. San José: Editorial de Costa Rica.

Selden, Raman. 2008. Teoría literaria contemporánea. Barcelona: Editorial Ariel.

Tordera, Antonio. 1979. "Teoría y técnica del análisis teatral", Elementos para una semiótica del texto artístico. Madrid: Editorial Cátedra.

Vargas Vargas, José Angél \& Vásquez Vargas, Magdalena. 1987. Las fisgonas de Paso Ancho y El martirio del Pastor: dos perspectivas de la obra dramática de Samuel Rovinski. Tesis para optar por Licenciatura en Filología española. San José: Universidad de Costa Rica.

Vladich, Stoyan. 1979. Notas para una historia del teatro costarricense. Revista Escena 4: $36-41$.

Zavala, Magda. 1972. Promoción teatral y teatro popular en Costa Rica. Revista Escena 2: 71-79).

\section{(ㅇ) $\odot \Theta \Theta$}

Este obra está bajo una licencia de Creative Commons Reconocimiento-NoComercial-SinObraDerivada 4.0 Internacional. 
